\title{
Perancangan dan Optimasi Antena Vivaldi pada Sistem Radar Penembus Permukaan (Ground Penetrating Radar)
}

\author{
BASO MARUDDANI ${ }^{1,2}$, EFRI SANDI ${ }^{1}$, MUHAMMAD FADHIL NAUFAL SALAM ${ }^{1}$ \\ ${ }^{1}$ Fakultas Teknik, Universitas Negeri Jakarta \\ ${ }^{2}$ DJA Institute, Jakarta \\ Email: basomaruddani@unj.ac.id
}

Received 26 November 2018 | Revised 17 Desember 2018 | Accepted 7 Januari 2019

\begin{abstract}
ABSTRAK
Antena Vivaldi merupakan salah satu jenis antena yang diimplementasikan pada radar penembus permukaan (Ground Penetrating Radar, GPR). GPR adalah salah satu metode non-destructive testing yang biasa digunakan untuk mengetahui kondisi beton/jalan raya. Penelitian ini merancang sebuah antena Vivaldi untuk digunakan pada GPR dengan frekuensi kerja $1 \mathrm{GHz}-2 \mathrm{GHz}$. Metode yang digunakan untuk merancang dan mengoptimasi antena Vivaldi adalah dengan mengubah beberapa parameter untuk mencapai spesifikasi yang diinginkan. Parameter tersebut antara lain lebar antena, panjang antena dan tapered slot. Optimasi yang dilakukan tetap memperhatikan pola radiasi antena agar tetap terarah. Hasil penelitian ini menghasilkan antena Vivaldi dengan dimensi 350x300 mm dengan return loss di bawah $-10 \mathrm{~dB}$ pada rentang frekuensi $1 \mathrm{GHz}-2 \mathrm{GHz}$. Hasil penelitian juga menunjukkan bahwa perubahan nilai parameter lebar antena dan tapered slot menggeser frekuensi kerja antena secara signifikan.
\end{abstract}

Kata kunci: Ground Penetrating Radar, Vivaldi, return loss, parameter antena

\begin{abstract}
The Vivaldi antenna is one type of antenna that is implemented on Ground Penetrating Radar (GPR). GPR is one of the non-destructive testing methods commonly used to determine the condition of concrete / highway. This studyaim to design a Vivaldi antenna to be used on GPR with a working frequency of $1 \mathrm{GHz}$ - $2 \mathrm{GHz}$. The method that used to design and optimize Vivaldi antennas is by changing several parameters to achieve the desired specifications. These parameters include antenna width, antenna length and tapered slot. Optimization carried out still observes the radiation pattern of the antenna to keep it directed. The results showed that $350 \times 300 \mathrm{~mm}$ antennas with return loss below $-10 \mathrm{~dB}$ in the frequency range of $1 \mathrm{GHz}-2 \mathrm{GHz}$. The results also show that changes in the parameter width of the antenna and tapered slots shift the antenna working frequency significantly.
\end{abstract}

Keywords: Ground Penetrating Radar, Vivaldi, return loss, antenna parameter 


\section{PENDAHULUAN}

Teknologi radar digunakan untuk mendeteksi benda kian berkembang pesat, baik yang berada di udara, di balik dinding, maupun di dalam tanah. Untuk implementasinya, radar dapat menggunakan gelombang suara maupun gelombang elektromagnetik. Pada radar yang menggunakan gelombang suara untuk mendeteksi benda diam sudah diteliti oleh (Renaldi, Hadiyoso, \& Ramadan, 2018). Pemanfaatan gelombang suara digunakan sebagai solusi penginderaan objek. Pada penelitian (Paulet, Salceanu, \& Neacsu, 2016) dikembangkan suatu radar dengan library yang spesifik sebagai antar muka sensor dan Arduino. Kekurangan dari pemanfaatan gelombang suara pada radar adalah ketelitian dan resolusi yang kurang untuk menginderakan objek pada jarak jauh serta gelombang suara yang membutuhkan media untuk perambatan gelombangnya. Untuk mendeteksi benda pada jarak yang jauh dan resolusi yang tinggi, radar menggunakan gelombang elektromagnetik. Salah satu aplikasinya adalah Radar Penembus Permukaan atau yang dikenal sebagai GPR (Ground Penetrating Radar). GPR adalah suatu alat pencitra yang menggunakan gelombang elektromagnetik untuk melihat material yang berada di bawah tanah. GPR dikembangkan pada berbagai disiplin ilmu seperti groundwater contamination, geotechnical, engineering, sedimentology, glaciology, dan archaeology. Penggunaan GPR dibedakan berdasarkan material yang ingin dipetakan tanpa harus merusak struktur yang ada. Setiap material membutuhkan spesifikasi sistem yang berbeda untuk dapat mendeteksi material tersebut. Material yang dimaksud bisa mineral, batu, kayu, logam, kedalaman tanah, maupun kedalaman permukaan air. Selain untuk mendeteksi material yang terkubur, GPR dalam pengembangannya ada yang digunakan untuk menembus dinding dan untuk kepentingan keamanan dan pertahanan, misalnya GPR digunakan untuk mendeteksi keberadaan ranjau (Hariyadi \& Mukhidin, 2015). Saat awal kemunculannya, teknologi GPR digunakan untuk mendeteksi material alami. Namun seiring dengan perkembangan teori dan tekniknya, GPR digunakan pula mendeteksi material yang tidak alami seperti aspal, beton, bahkan struktur jembatan.

Secara sederhana, cara kerja GPR adalah menghitung pantulan ataupun penyebaran gelombang elektromagnetik yang ditembakkan ke suatu permukaan. Jenis material yang akan dipetakan dan resolusi GPR ditentukan oleh antena dan frekuensi yang digunakan. Antena merupakan salah satu sub-sistem yang berperan penting terhadap kinerja GPR. Oleh karena itu, pada GPR dibutuhkan antena yang memiliki karakteristik bandwidth yang lebar dan beam yang sempit. Dalam hal ini, antena Vivaldi merupakan salah satu jenis antena yang dapat memenuhi kebutuhan untuk pengaplikasian GPR karena antena Vivaldi memiliki lebar bandwidth yang cukup luas dan pola radiasi yang terarah karena beam yang sempit. Antena Vivaldi termasuk kedalam golongan Tapered Slot Antenna (TSA) dimana antena Vivaldi memiliki struktur logam (patch) yang meruncing di satu sisinya. Antena Vivaldi cukup menjawab kebutuhan antena untuk sistem GPR.

Konsep antena Vivaldi pertama kali diperkenalkan oleh Gibson (Gibson, 1979). Antena Vivaldi dapat bekerja dengan bandwidth yang lebar, gain yang tinggi, pola radiasi yang terarah dan side lobe yang rendah (Rajaraman, 1999). Antena Vivaldi ini cukup banyak digunakan untuk keperluan radar. Antena Vivaldi yang dibahas pada makalah ini berbasis mikrostrip dimana antena mikrostrip memiliki kelebihan struktur yang planar, dan juga biaya fabrikasi yang relatif murah (Shuppert, 1988). Antena mikrostrip memiliki kelemahan yang berbanding terbalik dengan antenna Vivaldi yaitu sempitnya bandwidth dan kecilnya gain. Penelitian tentang antena Vivaldi dan karakteristiknya sudah banyak diteliti antara lain pada (Gazit, 1988) yang mengembangkan dan menginvestigasi antena Vivaldi dan perubahan feeding dari microstripe ke slot line. Hal tersebut mempengaruhi beamwidth antena. Pada (Gazit, 1988) juga diinvestigasi perubahan panjang antena yang digunakan sebagai fungsi 
kontrol terhadap bandwidth. Pada (Sharp \& Kyprianou, 2007) perubahan parameter antenna diinvestigasi antara lain perubahan bentuk antena, penggunaan material dielektrik antena dan ketebalan substrat terhadap lebar bandwidth. Novelti pada penelitian ini adalah peneliti mengobservasi perubahan beberapa nilai parameter antena terhadap perubahan bandwidth antena Vivaldi. Parameter tersebut antara lain panjang antena, lebar antena dan tapered slot. Peneliti menyimulasikan antena mikrostrip Vivaldi dengan optimasi agar antena yang dibuat memiliki bandwidth yang lebar dengan mengubah beberapa parameter dimensi antena.

Desain GPR ditentukan oleh material apa yang akan dipetakan oleh aplikasi. Hal ini dikarenakan setiap material memiliki nilai permitivitas dielektrik relatif yang berbeda beda. Frekuensi kerja yang digunakan akan menentukan material yang akan dideteksi begitupun sebaliknya, material yang akan dipetakan akan menentukan pada frekuensi berapa antena GPR akan dibuat. Lebarnya bandwidth juga dapat menentukan bagaimana kinerja aplikasi GPR.

Lebar bandwidth menentukan bagaimana resolusi yang diterima. NDT (Non-Destructive Testing) Transportation merupakan salah satu hasil pengembangan teknologi GPR untuk material infrastruktur jalan. Air-coupled system antennas terpasang dalam posisi tergantung pada NDT Transportation pada frekuensi $500 \mathrm{MHz}-2.5 \mathrm{GHz}$. Kelebihan menggunakan aircoupled system antennas adalah proses pengambilan data bisa dilakukan di atas kendaraan yang melaju dengan kecepatan tinggi hingga mencapai kecepatan $100 \mathrm{~km} / \mathrm{jam}$ (Jol, 2008).

\section{DESAIN DAN PERANCANGAN ANTENA}

\subsection{Antena Vivaldi}

Antena Vivaldi pertama kali diperkenalkan oleh Gibson pada tahun 1979 yang memiliki karakteristik bandwidth yang lebar dan pola radiasi directional (Hariyadi \& Mukhidin, 2015). Antena Vivaldi secara teoritis memiliki bandwidth yang tak terhingga dan gain yang signifikan serta memiliki polarisasi linear (Gibson, 1979). Antena Vivaldi termasuk ke dalam jenis Exponential Tapered Slot Antena (TSA). Gambar 1 menunjukkan desain tradisional Vivaldi mengacu pada desain awal yang diperkenalkan oleh Gibson dan Gambar 2 adalah implementasi antena Vivaldi yang diperkenalkan oleh Gibson.

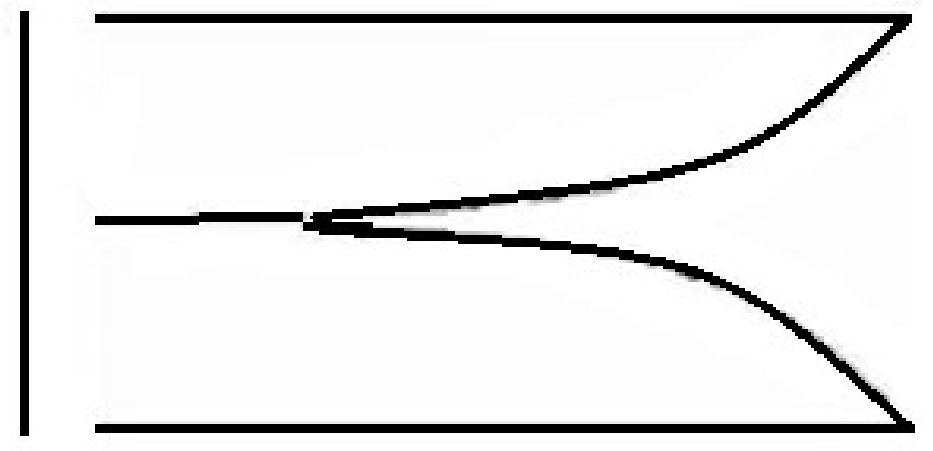

Gambar 1. Desain Tradisional Antena Vivaldi 


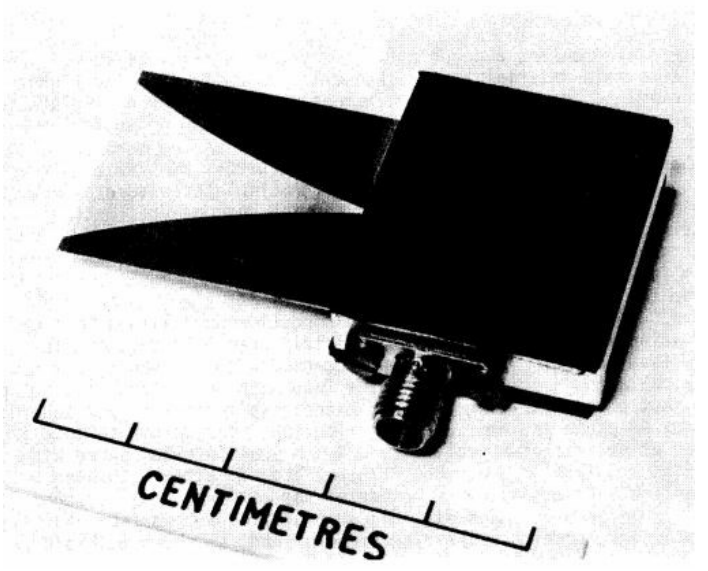

Gambar 2. Antena Vivaldi Milik Gibson pada Tahun 1979 Frekuensi Kerja 8ghz-40ghz

Pada penelitian ini, perancangan taper slot meliputi perancangan panjang runcing dan juga nilai tapered rate. Dengan menjumlahkan Tapered Length, panjang Slot Line, Backwall Offset akan menghasilkan total panjang rancangan antena Vivaldi (Erdogan, 2009).

Pembuatan bidang lancip antena vivaldi berdasarkan fungsi eksponensial pada rumus,

$$
u= \pm s \times \exp ^{(r \times t)}
$$

$u$ dan $t$ menunjukan titik dimensi bidang lancip pada antena vivaldi. $s$ menunjukan titik terendah dari bidang lancip. Gambar 3 menunjukkan bagaimana dua fungsi eksponensial (masing masing dengan A dan $-\mathrm{A}$ ) membentuk tapered slot.

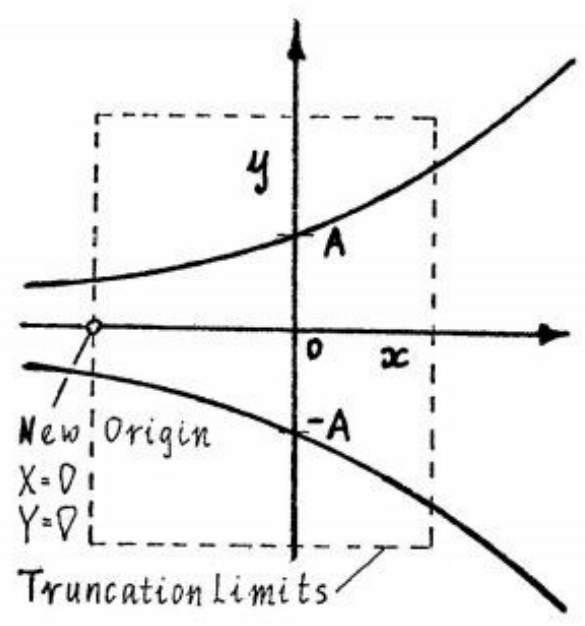

\section{Gambar 3. Tapered Slot Dibangun Oleh Dua Fungsi Eksponensial}

Tingkat kemiringan taper slot antena Vivaldi sangat berpengaruh terhadap gain, beamwidth dan bandwidth dari TSA (Rajaraman, 1999). Gambar 4 menunjukkan tampak depan dan parameter dimensi antena Vivaldi. 


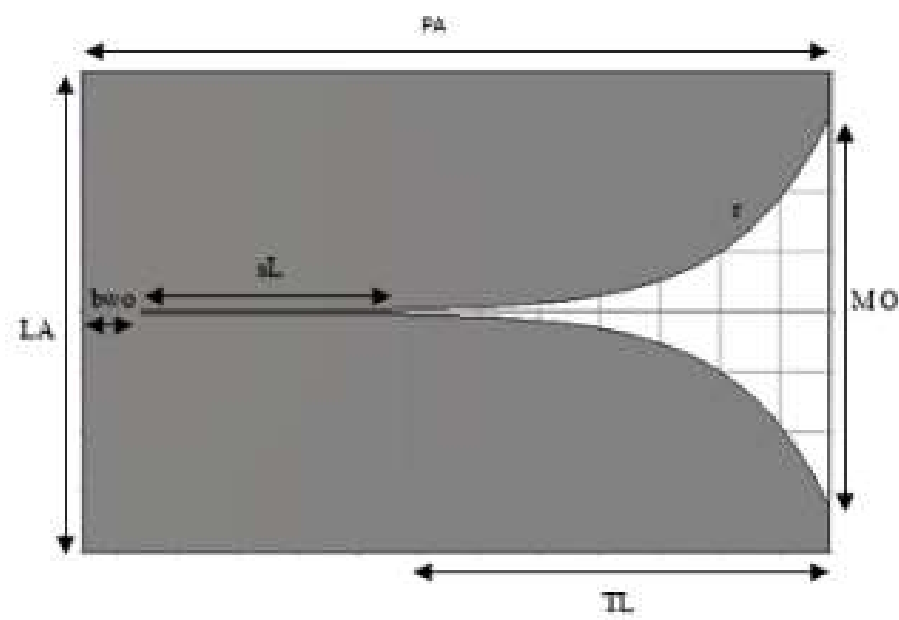

Gambar 4. Tampak Depan dan Parameter Dimensi Antena Vivaldi

keterangan:

$P A \quad$ : Panjang antena

$L A$ : Lebar Antena

Bwo : Backwall Offset

$T L \quad$ : Tapered Length

MO : Mouth Opening

$r \quad$ : Tapered Rate

sL : Slotline Length

\subsection{Perancangan desain antena}

Pada tahap perancangan desain antena Vivaldi ini, parameter dimensi antena ditentukan berdasarkan perhitungan beberapa parameter dimensi antena Vivaldi. Parameter parameter tersebut adalah panjang antena, lebar antena, tapered length, tapered rate, panjang slotline, lebar slotline, panjang stub dan panjang saluran mikrostip.

Pada (Erdogan, 2009) dijelaskan bahwa panjang dimensi antena dapat sama dengan atau lebih besar dari panjang gelombang untuk frekuensi kerja terendah dan lebar antena dapat kerjalebih besar sama dengan setengah panjang gelombang pada frekuensi terendah. Frekuensi terendah pada antena yang akan didesain adalah $1 \mathrm{GHz}$. Formula untuk mencari panjang antena, $(P A)$ dan lebar antena $(L A)$ berturut - turut ditunjukkan oleh Persamaan (2) dan Persamaan (3).

$$
\begin{gathered}
P A \approx \frac{c}{f_{1} \sqrt{\varepsilon_{r}}} \\
L A \approx \frac{1}{2} \times \frac{c}{f_{1} \sqrt{\varepsilon_{r}}}
\end{gathered}
$$

dimana $c$ adalah kecepatan cahaya, $f_{1}$ adalah frekuensi kerja terendah dan $\varepsilon_{r}$ adalah permitivitas relatif.

Untuk menghitung tapered length (TL) antena, dapat digunakan Persamaan (4) yang dijelaskan pada (Shan, Xu, \& Lin, 2017) bahwa nilai tapered length $(T L)$ sebesar setengah panjang gelombang memberikan efisiensi antena yang baik. Sementara tapered rate didapat dari rumus eksponensial yang pada penelitian kali ini dilambangkan dengan $r$. Semakin besar nilai $r$ semakin terbuka juga bidang lancip. Nilai $r$ mempengaruhi nilai dari mouth opening 
antena Vivaldi. Untuk meningkatkan efisiensi radiasi antena, nilai mouth opening yang disarankan adalah sebesar setengah panjang gelombang (Erdogan, 2009), dan bandwidth antena akan meningkat jika nilai mouth opening diperbesar. Maka nilai mouth opening dipilih sebesar setengah panjang gelombang dari frekuensi terendah. Formula untuk menghitung tapered rate $(r)$ antena ditunjukkan oleh Persamaan (5)

$$
\begin{gathered}
T L \approx \frac{1}{2} \times \frac{c}{f_{1} \sqrt{\varepsilon_{r}}} \\
\pm \frac{M O}{2}= \pm \frac{s}{2} \times \exp ^{(r \times T L)}
\end{gathered}
$$

Nilai dari panjang slotline dapat diketahui dari selisih panjang antena keseluruhan dengan backwall offset dan panjang taper slot. Panjang slotline sudah termasuk dengan panjang stub dengan nilai seperempat panjang gelombang dari titik temu slotline dengan mikrostrip. Formula untuk menghitung panjang slotline $(s L)$ antena dan lebar slotline $(s)$ antena berturut - turut ditunjukkan oleh Persamaan (6) dan Persamaan (7) (Yin, Wang, \& Zhao, 2016)

$$
\begin{gathered}
s L=P A-b w o-T L \\
s \approx \frac{c}{f_{2} \sqrt{\varepsilon_{r}}} \times 2 \%
\end{gathered}
$$

Stub adalah panjang material yang besarnya seperempat panjang gelombang. Stub terdiri dari panjang stub slotline dan panjang stub stripline atau mikrostrip (Rajaraman, 1999).

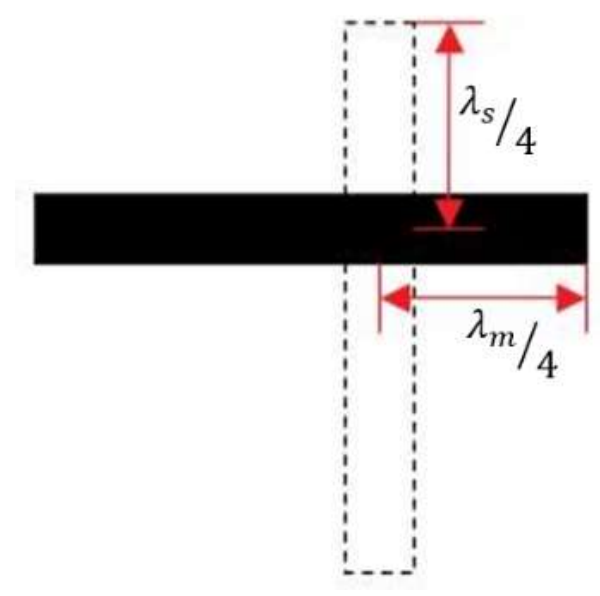

Gambar 5. Panjang Stub Slotline

Gambar 5 menunjukkan panjang stub slotline, $\lambda_{s}$, yang nilainya adalah seperempat panjang gelombang dan panjang stub mikrostrip, $\lambda_{m}$, yang nilainya adalah seperempat panjang gelombang. Formula untuk menghitung panjang stub (stubL) ditunjukkan oleh Persamaan (8)

$$
\text { stubL }=0.25 \times \frac{c}{f_{c} \sqrt{\varepsilon_{r}}}
$$

dimana $f_{c}$ adalah frekuensi tengah dari frekuensi kerja antena.

Parameter dimensi antena Vivaldi berdasarkan hasil perhitungan dirangkum dalam Tabel 1 dimana parameter tersebut ditentukan berdasarkan perhitungan dan studi literatur. 
Tabel 1. Parameter awal dimensi antena Vivaldi

\begin{tabular}{|l|c|l|}
\hline \multicolumn{1}{|c|}{ Parameter } & Lambang & \multicolumn{1}{c|}{ Nilai } \\
\hline Tapered length & $T L$ & $75 \mathrm{~mm}$ \\
\hline Tapered rate & $r$ & 0,0555 \\
\hline Mouth opening & $M O$ & $73,22 \mathrm{~mm}$ \\
\hline Panjang stub & stubL & $24,1 \mathrm{~mm}$ \\
\hline Panjang slotline & $s L$ & $74 \mathrm{~mm}$ \\
\hline Lebar slotline & $S$ & $1,14 \mathrm{~mm}$ \\
\hline Panjang antena & $P A$ & $150 \mathrm{~mm}$ \\
\hline Lebar antena & $L A$ & $75 \mathrm{~mm}$ \\
\hline Tebal cooper & - & $0,035 \mathrm{~mm}$ \\
\hline Tebal substrat & $H$ & $1,6 \mathrm{~mm}$ \\
\hline Backwall offset & $B w o$ & $1 \mathrm{~mm}$ \\
\hline Lebar mikrostrip & $W$ & $3,1 \mathrm{~mm}$ \\
\hline
\end{tabular}

Langkah berikutnya adalah menyimulasikan antena dengan parameter seperti yang dituliskan pada Tabel 1 menggunakan perangkat lunak simulasi antena dengan elemen substrat yang digunakan adalah material epoxy (FR4) yang memiliki konstanta dielektrik 4,4 dan tebal 1,6 $\mathrm{mm}$. Model antena Vivaldi yang akan disimulasikan ditunjukkan oleh Gambar 6.

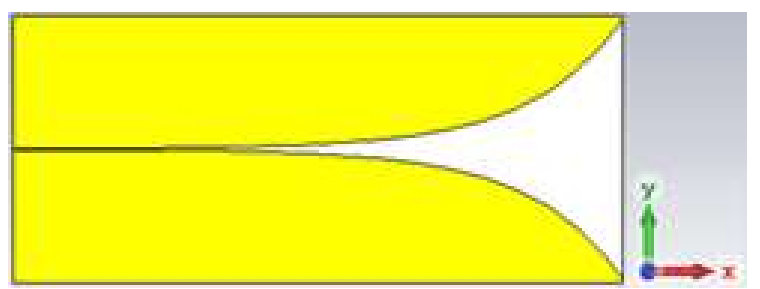

Tampak Depan

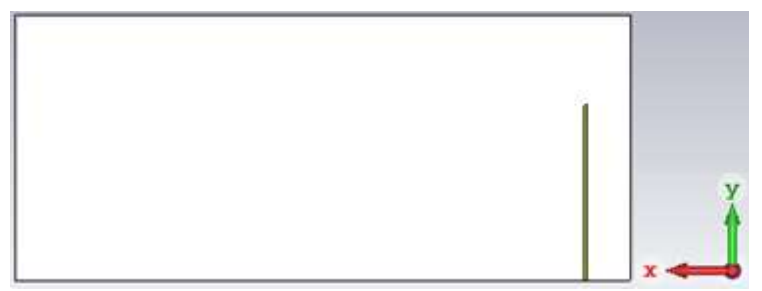

Tampak Belakang

Gambar 6. Antena Vivaldi yang akan Disimulasikan dengan Parameter Awal

\section{HASIL DAN DISKUSI}

Proses simulasi akan menghasilkan nilai-nilai parameter performansi antena yang dirancang sehingga pada saat proses fabrikasi performa antena sudah dapat diketahui kemampuannya. Untuk mendapatkan frekuensi kerja sesuai spesifikasi yang diinginkan, maka nilai return loss pada rentang frekuensi $1 \mathrm{GHz}-2 \mathrm{GHz}$ haruslah bernilai dibawah $-10 \mathrm{~dB}$. Terlihat pada Gambar 7, nilai return loss yang didapatkan belum sesuai dengan yang diharapkan. Untuk mendapatkan hasil yang diharapkan, parameter yang terdapat pada Tabel 1 kemudian dioptimasi. Metode optimasi yang dilakukan adalah mengubah beberapa parameter, yaitu panjang antena, lebar antena dan tapered slot (tapered length dan tapered rate), untuk melihat seperti apa perubahan ketiga parameter tersebut terhadap frekuensi kerja antena. 


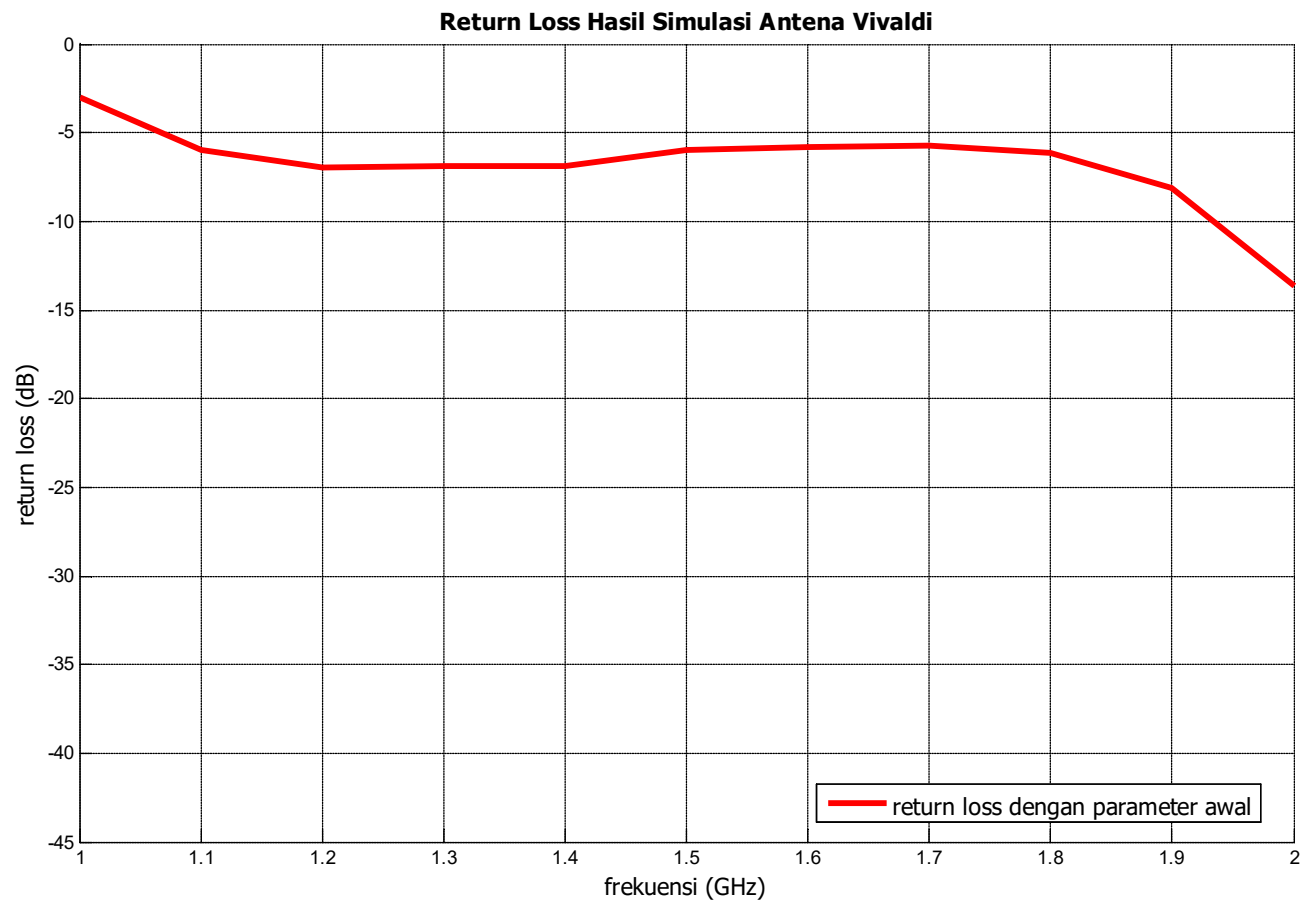

Gambar 7. Return Loss Hasil Simulasi Antena Vivaldi dengan Parameter Awal (Tabel 1)

Proses optimasi dilakukan dengan mengubah secara bertahap satu parameter dengan mempertahankan nilai parameter yang lain. Untuk proses pertama, dilakukan dengan mengubah parameter panjang antena. Optimasi panjang antena dilakukan dengan melakukan penambahan nilai parameter panjang antena dengan catatan bahwa perubahan nilai ini tidak mempengaruhi nilai tapered length dan panjang stub slotline walaupun panjang slotline ikut berubah. Perubahan parameter panjang antena diubah bertahap yaitu nilainya menjadi 200 $\mathrm{mm}, 250 \mathrm{~mm}, 300 \mathrm{~mm}$, dan $350 \mathrm{~mm}$. Gambar 8 menunjukkan grafik perbandingan nilai return loss terhadap beberapa nilai parameter panjang antena.

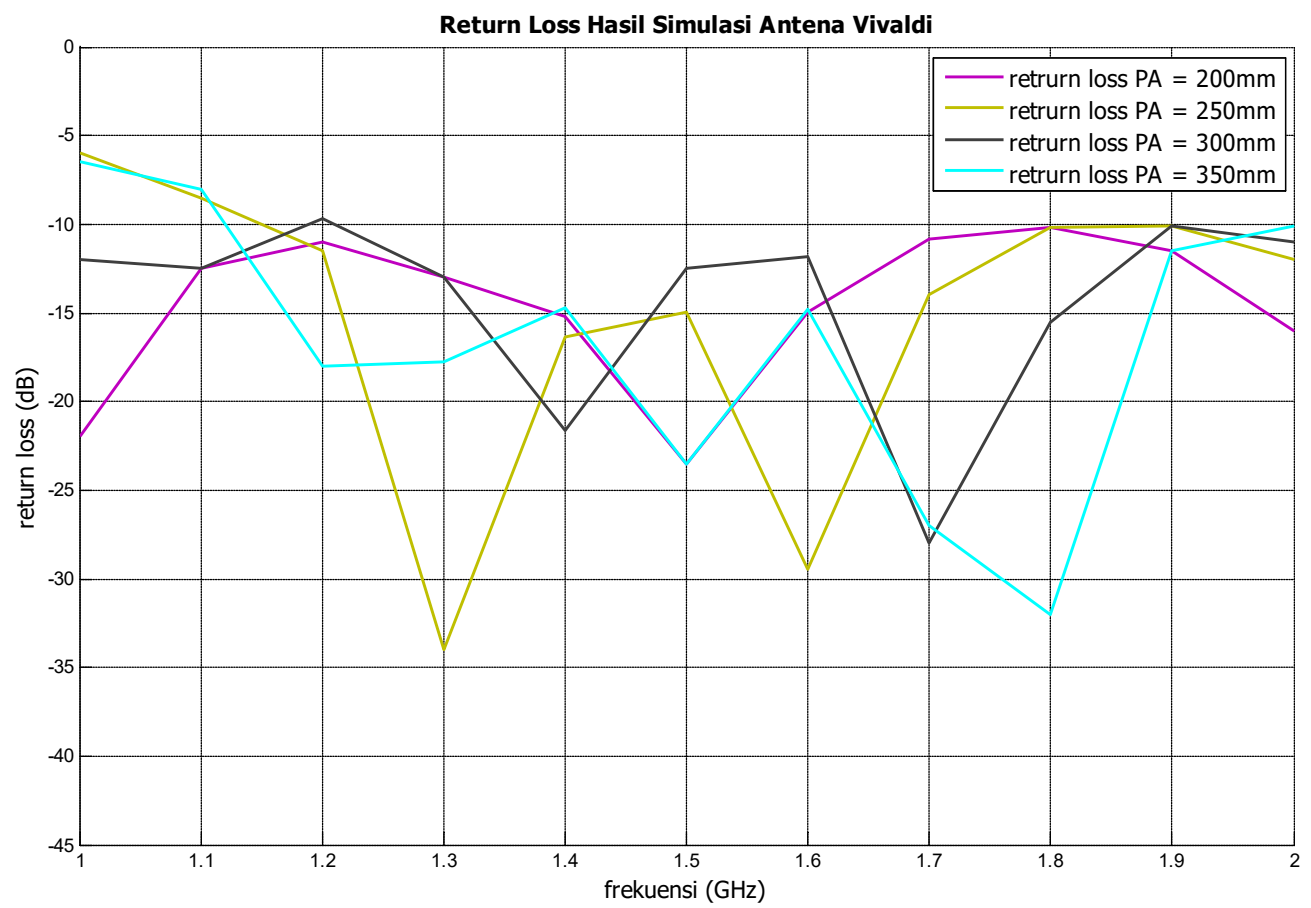

Gambar 8. Grafik Return Loss Terhadap Perubahan Bertahap Nilai Panjang Antena, PA 
Gambar 8 di atas memperlihatkan bahwa perubahan nilai panjang antena berpengaruh terhadap nilai return loss. Ketika panjang antena diperbesar maka nilai return loss pada rentang $1-2 \mathrm{GHz}$ secara umum menjadi mengecil walaupun tidak signifikan. Dengan menambah panjang antena ini dapat menurunkan titik puncak return loss yang hampir menyentuh $-10 \mathrm{~dB}$. Oleh karenanya, melihat hasil simulasi dengan penambahan nilai panjang antena, maka panjang antena yang dipilih adalah $350 \mathrm{~mm}$.

Proses optimasi yang kedua adalah dengan melakukan perubahan bertahap terhadap nilai parameter lebar antena. Perubahan nilai lebar antena ini berpengaruh terhadap panjang saluran mikrostrip namun tidak mempengaruhi panjang stub. Perubahan nilai parameter lebar antena dilakukan secara bertahap yaitu $75 \mathrm{~mm}, 100 \mathrm{~mm}, 125 \mathrm{~mm}, 200 \mathrm{~mm}$ dan $250 \mathrm{~mm}$. Gambar 9 menunjukkan grafik perbandingan nilai return loss terhadap beberapa nilai parameter lebar antena.

Terlihat pada Gambar 9, hasil simulasi penambahan nilai parameter lebar antena membuat nilai return loss menjadi semakin rendah pada rentang frekuensi yang diinginkan. Melihat hasil simulasi tersebut, maka optimasi lebar antena dilakukan dengan memperlebar dimensi antena mencapai nilai $300 \mathrm{~mm}$.

Proses optimasi berikutnya adalah dengan melakukan perubahan bertahap terhadap nilai tapered slot. Optimasi nilai parameter tapered slot ini dilakukan dengan mengubah nilai tapered length dan nilai tapered rate. Hal tersebut dilakukan agar bentuk antena tetap proporsional dengan konsep antena Vivaldi yang dibuat oleh Gibson. Gambar 10 menunjukkan grafik perbandingan nilai return loss terhadap beberapa nilai tapered slot.

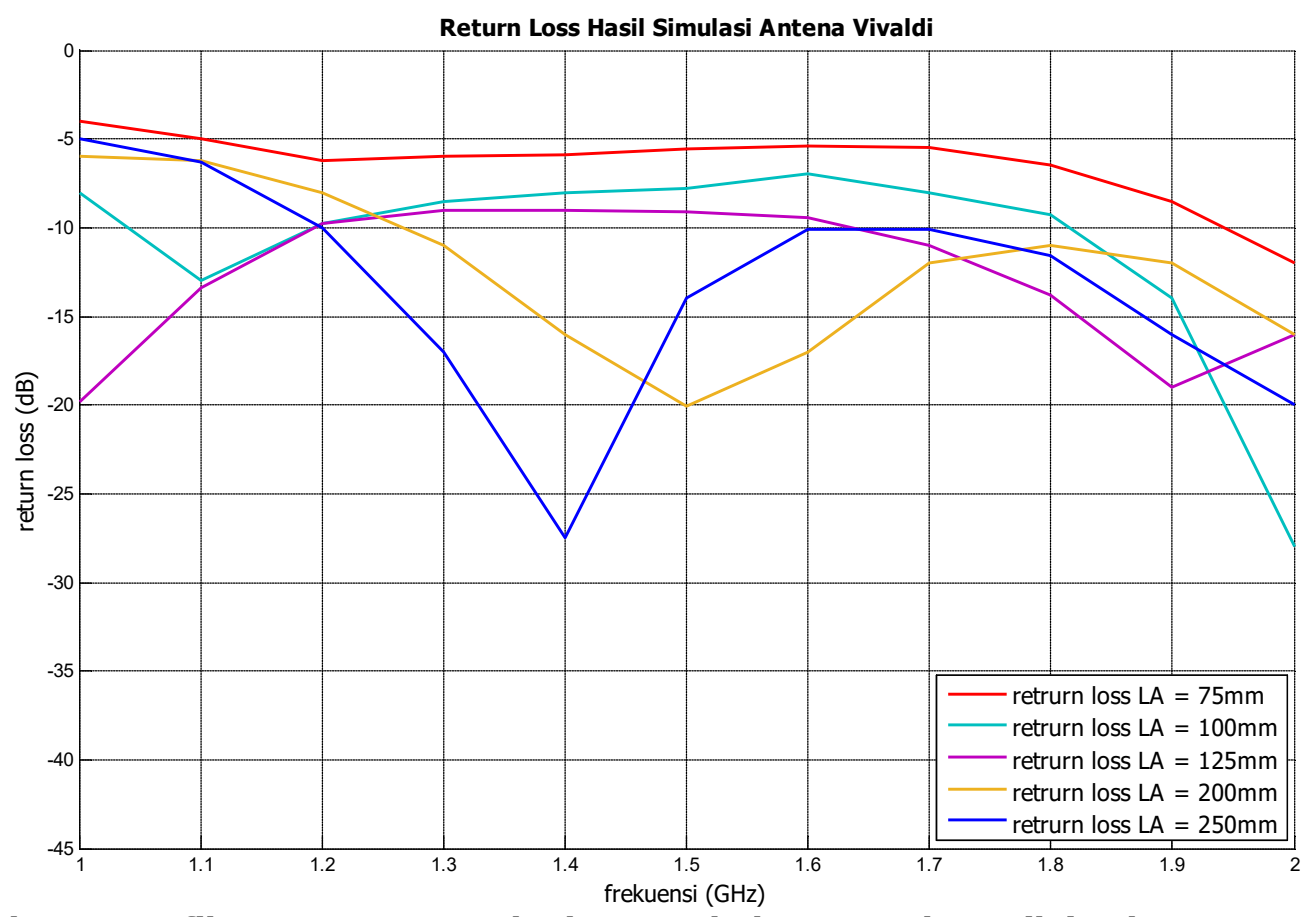

Gambar 9. Grafik Return Loss Terhadap Perubahan Bertahap Nilai Lebar Antena, LA 


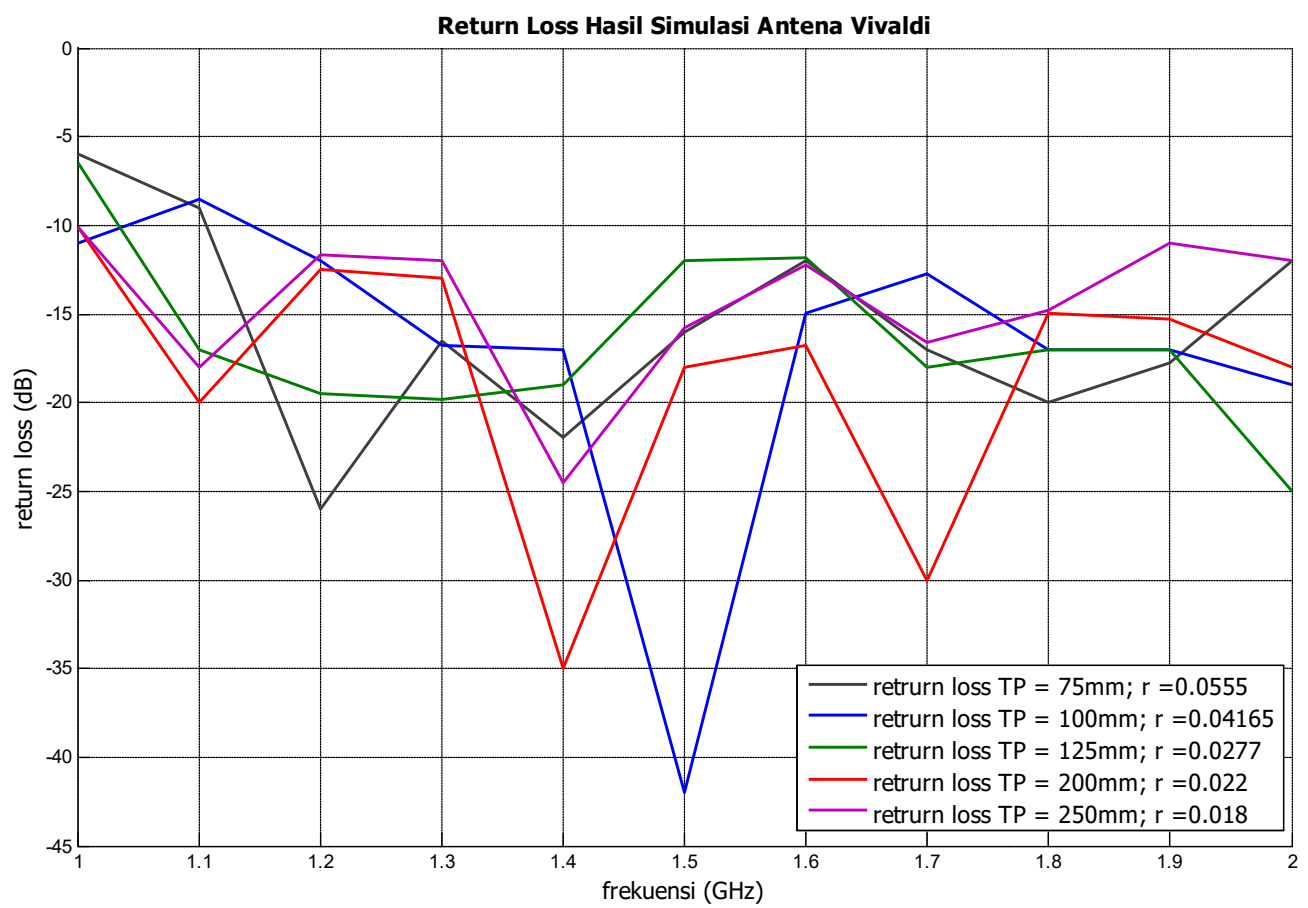

Gambar 10. Grafik Return Loss Terhadap Perubahan Nilai Tapered Slot, TL

Gambar 10 menunjukkan hasil simulasi return loss yang dihasilkan oleh perubahan nilai tapered slot. Hasil simulasi menunjukkan bahwa pengubahan nilai tapered length (mouth opening, tapered length dan tapered rate) menjadi lebih besar membuat nilai return loss semakin mengecil. Oleh karenanya, nilai tapered slot yang dipilih adalah $250 \mathrm{~mm}$ dan dirangkum pada Tabel 2.

Tabel 2. Nilai Tapered Slot Setelah Proses Optimasi

\begin{tabular}{|l|l|}
\hline \multicolumn{1}{|c|}{ Parameter } & \\
\hline Tapered length & $250 \mathrm{~mm}$ \\
\hline Tapered rate & 0.022 \\
\hline Mouth opening & $278,95 \mathrm{~mm}$ \\
\hline
\end{tabular}

Tabel 3. Parameter Dimensi Antena Vivaldi Setelah Optimasi

\begin{tabular}{|l|c|l|l|}
\hline \multicolumn{1}{|c|}{ Parameter } & Lambang & \multicolumn{1}{c|}{ Nilai awal } & \multicolumn{1}{c|}{ Nilai setelah optimasi } \\
\hline Tapered Length & $T L$ & $75 \mathrm{~mm}$ & $250 \mathrm{~mm}$ \\
\hline Tapered Rate & $r$ & 0,0555 & 0,022 \\
\hline Mouth Opening & $M O$ & $73,22 \mathrm{~mm}$ & $278,95 \mathrm{~mm}$ \\
\hline Panjang stub & $s t u b L$ & $24,1 \mathrm{~mm}$ & $24,1 \mathrm{~mm}$ \\
\hline Panjang slotline & $s L$ & $74 \mathrm{~mm}$ & $99 \mathrm{~mm}$ \\
\hline Lebar slotline & $S$ & $1,14 \mathrm{~mm}$ & $1,14 \mathrm{~mm}$ \\
\hline Panjang Antena & $P A$ & $150 \mathrm{~mm}$ & $350 \mathrm{~mm}$ \\
\hline Lebar Antena & $L A$ & $75 \mathrm{~mm}$ & $300 \mathrm{~mm}$ \\
\hline Tebal cooper & - & $0,035 \mathrm{~mm}$ & $0,035 \mathrm{~mm}$ \\
\hline Tebal Substrat & $H$ & $1,6 \mathrm{~mm}$ & $1,6 \mathrm{~mm}$ \\
\hline Backwall offset & $B w O$ & $1 \mathrm{~mm}$ & $1 \mathrm{~mm}$ \\
\hline Lebar mikrostrip & $W$ & $3,1 \mathrm{~mm}$ & $3 \mathrm{~mm}$ \\
\hline
\end{tabular}


Setelah proses optimasi dilakukan dengan mengubah bertahap nilai parameter panjang antena, lebar antena dan nilai tapered slot, maka dilakukan simulasi dengan nilai parameter antena terpilih. Tabel 3 dan Gambar 11 berturut-turut menunjukan perbandingan parameter antena Vivaldi sebelum dan setelah proses optimasi, dan ukuran desain antena Vivaldi setelah optimasi.

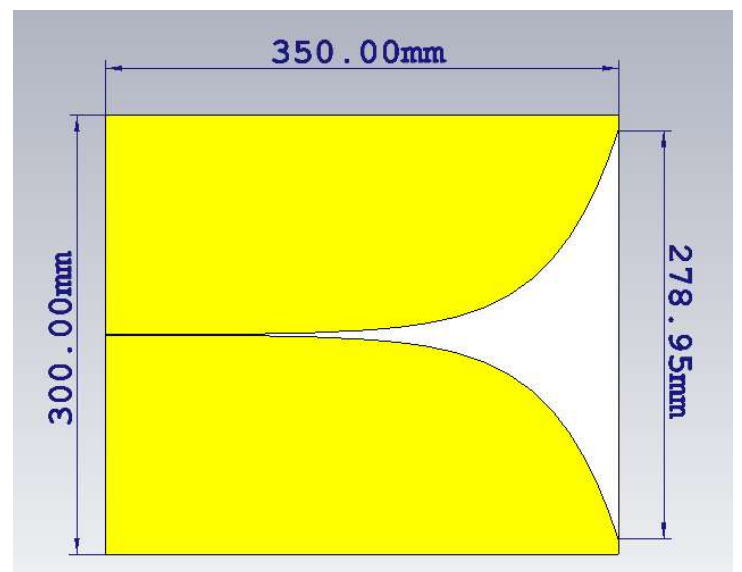

Gambar 11. Desain Antena Vivaldi Hasil Optimasi

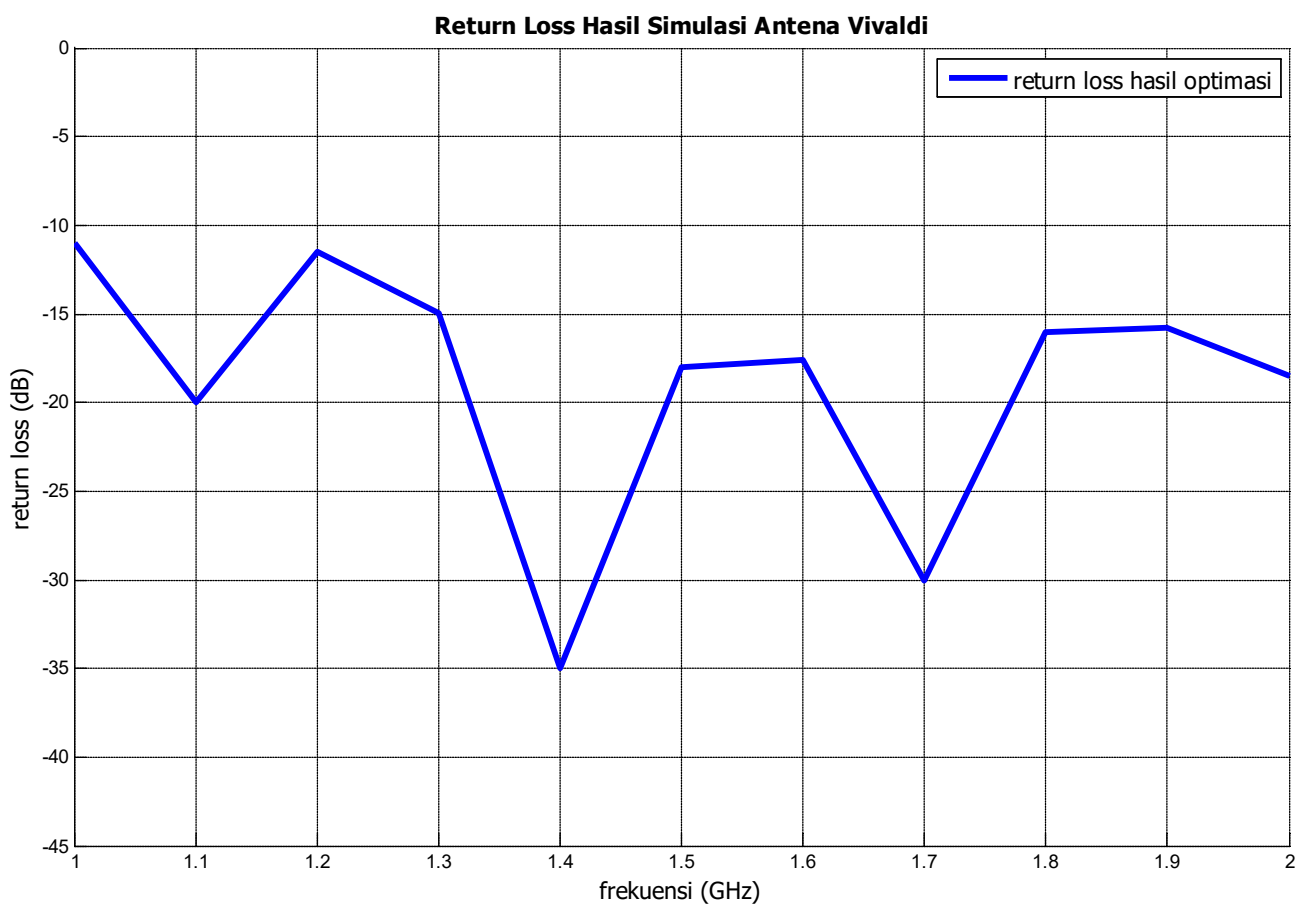

Gambar 12. Grafik Return Loss Antena Vivaldi Setelah Optimasi

Setelah dilakukan optimasi pada tiga parameter dimensi antena vivaldi yaitu panjang antena, lebar antena dan tapered slot setiap parameter memiliki pengaruh yang berbeda beda terhadap parameter return loss. Tabel 4 menjelaskan rangkuman dari hasil perubahan parameter antena Vivaldi. 
Tabel 4. Analisis Optimasi Parameter Dimensi Antena Vivaldi

\begin{tabular}{|l|l|}
\hline \multicolumn{1}{|c|}{ Parameter } & \multicolumn{1}{|c|}{ Analisis } \\
\hline Panjang antena & $\begin{array}{l}\text { Pada saat nilai panjang antena diperbesar, tidak terlihat } \\
\text { perubahan grafik return loss yang signifikan terhadap rentang } \\
\text { frekuensi kerja antena Vivaldi. Tetapi, dengan nilai panjang } \\
\text { antena yang lebih besar dari lebar antena ini bertujuan agar } \\
\text { antena vivaldi yang dibuat tetap memiliki pola radiasi yang } \\
\text { menjadi ciri khas dari antena vivaldi. }\end{array}$ \\
\hline Lebar antena & $\begin{array}{l}\text { Pada saat nilai lebar antena diperbesar, nilai return loss } \\
\text { berangsur turun. Ini mengakibatkan lebar pita memiliki nilai } \\
\text { yang lebih besar ketika nilai parameter lebar antena diperbesar. }\end{array}$ \\
\hline Tapered slot & $\begin{array}{l}\text { Pada saat nilai tapered slotyang meliputi nilai tapered rate dan } \\
\text { tapered length diperbesar nilainya, rentang frekuensi kerja } \\
\text { antena vivaldi bergeser ke arah frekuensi yang lebih rendah } \\
\text { sama halnya ketika nilai parameter lebar antena diubah. Ini } \\
\text { mengakibatkan ketika tapered length diperbesar dan tapered } \\
\text { rate diperkecil, rentang frekuensi kerja semakin lebar. Namun } \\
\text { optimasi tapered slot dibatasi oleh lebar antena dan panjang } \\
\text { antena karena letaknya yang berada didalam dimensi panjang } \\
\text { dan lebar antena vivaldi. }\end{array}$ \\
\hline
\end{tabular}

Setelah simulasi dilakukan, desain antena kemudian difabrikasi dengan parameter - parameter hasil optimasi dan kemudian dilakukan pengukuran terhadap antena yang telah difabrikasi. Antena hasil fabrikasi dan hasil pengukuran berturut - turut ditunjukkan pada Gambar 13 dan Gambar 14. Dari hasil pengukuran return loss terhadap antena yang telah difabrikasi pada Gambar 14 memperlihatkan bahwa lebar bandwidth antena adalah $700 \mathrm{MHz}$. Hal tersebut kemungkinan dikarenakan terdapat perbedaan parameter antara desain antena dan antena hasil fabrikasi yang sulit untuk dihindari, seperti lebar slotline, lebar mikrostip dan besarnya mouth opening. Namun secara umum, antena yang dihasilkan sudah memenuhi kriteria karena bandwitdhnya sudah cukup lebar, yaitu > $500 \mathrm{MHz}$.
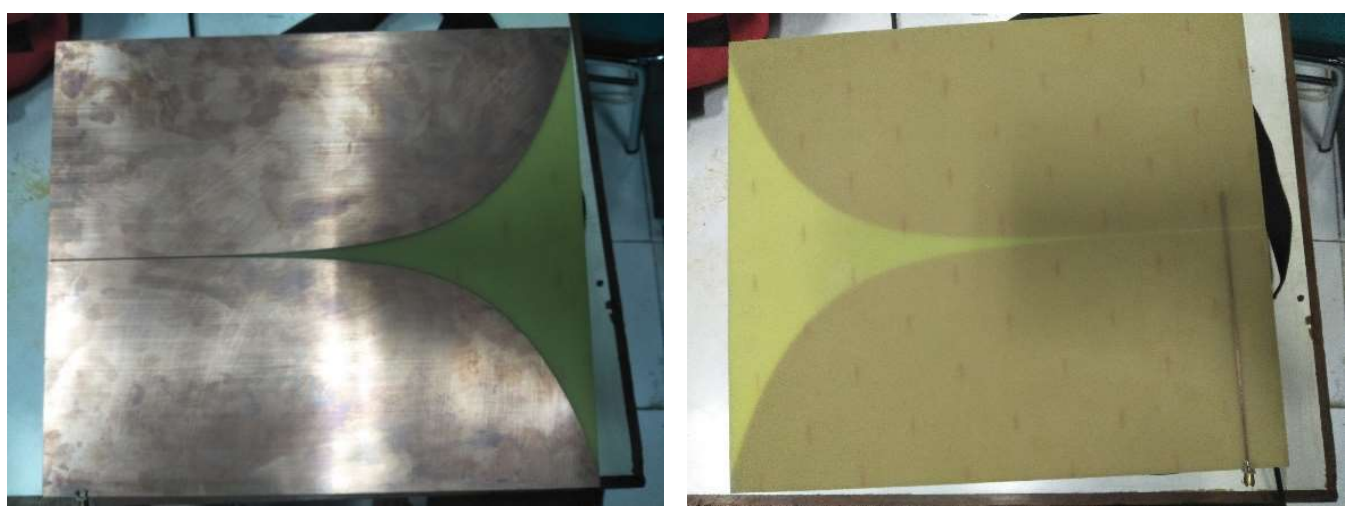

Gambar 13. Foto Antena Vivaldi yang telah Difabrikasi 


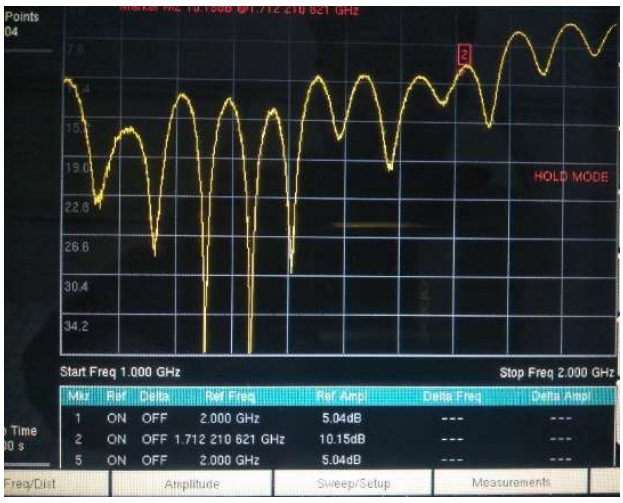

Gambar 14. Hasil Pengukuran Antena yang telah Difabrikasi

\section{KESIMPULAN}

Hasil perancangan dan hasil simulasi menunjukkan bahwa optimasi antena Vivaldi dapat dilakukan dengan mengubah nilai dari parameter antena yaitu panjang antena, lebar antena, tapered length dan tapered rate. Perubahan nilai parameter panjang antena dapat menurunkan nilai return loss lebih dalam pada rentang frekuensi tertentu, namun secara umum tidak terlalu mempengaruhi perubahan frekuensi kerja antena Vivaldi. Sedangkan perubahan nilai parameter lebar antena dan tapered slot memberikan efek yang cukup signifikan dalam mencapai spesifikasi antena Vivaldi yang diinginkan. Penambahan nilai parameter lebar antena membuat bandwidth antena Vivaldi membesar ke arah frekuensi yang lebih rendah. Begitu pula dengan penambahan nilai parameter tapered length dan tapered rate juga membuat bandwidth antena Vivaldi membesar ke arah frekuensi yang lebih rendah.

\section{DAFTAR RUJUKAN}

Erdogan, Y. (2009). Parametric Study and Design of Vivaldi Antennas and Arrays. Ankara, Turki: Middle East Technical University. https://doi.org/10.1063/1.1328410

Gazit, E. (1988). Improved design of the Vivaldi antenna. In IEE Proceedings $H$ Microwaves, Antennas and Propagation. https://doi.org/10.1049/ip-h-2.1988.0020

Gibson, P. J. (1979). The Vivaldi Aerial. In 1979 9th European Microwave Conference (pp. 101-105). https://doi.org/10.1109/EUMA.1979.332681

Hariyadi, T., \& Mukhidin, M. (2015). Studi Parametrik Antena Vivaldi Slot dengan Pencatuan Mikrostrip. In Seminar Nasional Teknologi (SENATEK) 2015 (pp. 397-403). Malang: Institut Teknologi Nasional Malang.

Jol, H. M. (2008). Ground Penetrating Radar Theory and Applications. Oxford: Elsevier Science. Paulet, M. V, Salceanu, A., \& Neacsu, O. M. (2016). Ultrasonic radar. In 2016 International Conference and Exposition on Electrical and Power Engineering (EPE) (pp. 551-554). Iasi, Romania. https://doi.org/10.1109/ICEPE.2016.7781400

Rajaraman, R. (1999). Design Of a Wideband Vivaldi Antenna Array for the Snow Radar. Kansas: University of Kansas. 
Renaldi, L., Hadiyoso, S., \& Ramadan, D. N. (2018). Purwarupa Radar sebagai Pendeteksi Benda Diam menggunakan Ultrasonik. Jurnal ELKOMIKA, 6(3), 317-327. https://doi.org/10.26760/elkomika.v6i3.317

Shan, J., Xu, A., \& Lin, J. (2017). A parametric study of microstrip-fed Vivaldi antenna. In 2017 3rd IEEE International Conference on Computer and Communications (ICCC) (pp. 1099-1103). https://doi.org/10.1109/CompComm.2017.8322713

Sharp, A. N., \& Kyprianou, R. (2007). Vivaldi Antennas: Wideband radar antennas simulation and reality. In 2007 IET International Conference on Radar Systems (pp. 1-5). https://doi.org/10.1049/cp:20070607

Shuppert, B. (1988). Microstrip/slotline transitions: modeling and experimental investigation. IEEE Transactions on Microwave Theory and Techniques, 36(8), 1272-1282. https://doi.org/10.1109/22.3669

Yin, T., Wang, Y., \& Zhao, M. (2016). A design of modified Vivaldi antenna BT - 2016 5th International Conference on Advanced Materials and Computer Science (ICAMCS 2016). In 5th International Conference on Advanced Materials and Computer Science (ICAMCS 2016). Atlantis Press. https://doi.org/10.2991/icamcs-16.2016.145 